\title{
Outcome of vaginal birth after caesarean section in women with one previous section and spontaneous onset of labour
}

\author{
K.A. Frass ${ }^{7}$ and A.H. Al Harazi ${ }^{1}$
}

$$
\begin{aligned}
& \text { نتائج الولادة المهبلية التالية للقيصرية، في نساء أجريَتْ لهن قيصرية واحدة وبدأ المخاض عندهن تلقائياً }
\end{aligned}
$$

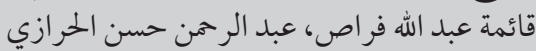

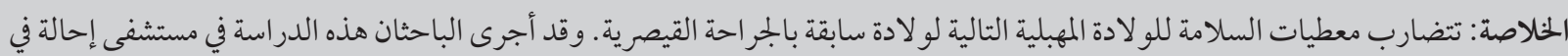

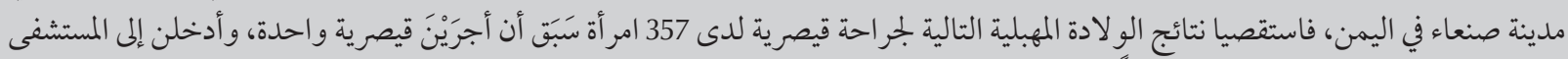

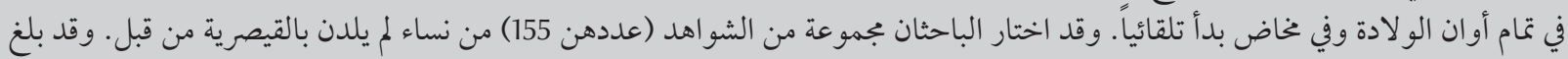

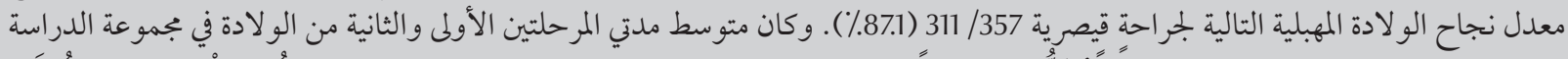

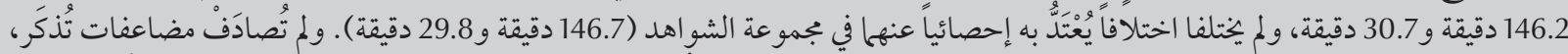

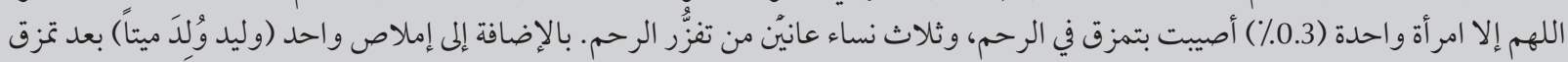

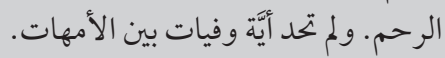

ABSTRACT The data about the safety of vaginal birth after caesarean section are conflicting. This study in a referral hospital in Sana'a, Yemen investigated the outcome of vaginal birth after caesarean section in 357 women who had one prior caesarean section and were admitted to hospital at term with spontaneous onset of labour. A control group ( $n=155$ ) was matched from women without previous caesarean section. The success rate of vaginal birth after caesarean section was 311/357 (87.1\%). The mean duration of the first and second stages of labour were not significantly different in the study group (146.2 and 30.7 min respectively) compared with the control group (146.7 and $29.8 \mathrm{~min})$. There were infrequent complications; only 1 woman $(0.3 \%)$ had ruptured uterus and 3 women (1.0\%) suffered uterine dehiscence. There was 1 stillbirth after the uterine rupture but no maternal deaths.

Résultats de l'accouchement par voie basse après déclenchement spontané du travail chez des femmes ayant eu une première césarienne

RÉSUMÉ Les données concernant la sécurité d'un accouchement par voie basse après une première césarienne sont discordantes. La présente étude réalisée dans un hôpital de recours à Sanaa (Yémen) a consisté à analyser les résultats des accouchements par voie basse de 357 femmes ayant eu une première césarienne et admises à I'hôpital à terme après le déclenchement spontané du travail. Un groupe témoin de femmes $(n=155)$ n'ayant jamais eu de césarienne a été apparié. Le taux de réussite d'un accouchement par voie basse après une première césarienne était de 87,1 \% (311 sur 357). La durée moyenne de la première et deuxième phases du travail n'était pas très différente entre le groupe de l'étude (146,2 et 30,7 minutes respectivement) et le groupe témoin (146,7 et 29,8 minutes). Les complications étaient rares; seule une femme $(0,3 \%)$ a souffert d'une rupture utérine et trois femmes $(1,0 \%)$ ont présenté une déhiscence utérine. Une mortinaissance a été observée après une rupture utérine mais aucun décès maternel n'a été déploré.

'Department of Obstetrics and Gynaecology, Faculty of Medicine, University of Sana'a, Sana'a, Yemen (Correspondence to K.A. Frass: kaimafrass@ hotmail.com).

Received: 30/09/09; accepted: 05/01/10 


\section{Introduction}

Trial of labour for vaginal birth after caesarean section (VBAC) is a wellestablished standard practice of care [1]. The success rates for VBAC range between $60 \%-80 \%$ after one previous lower segment caesarean incision $[2,3]$. Factors associated with successful vaginal birth in a trial of labour include age $<40$ years, prior history of vaginal birth, any indication for previous caesarean section except failure to progress in the first birth, cervical effacement greater than $75 \%$ on admission, and cervical dilatation $4 \mathrm{~cm}$ or more on admission [1]. However, not every woman with a previous caesarean scar is a candidate for VBAC as the trial could likely result in major maternal as well as fetal complications.

The risks of a failed trial, including uterine rupture, hysterectomy and longterm urinary incontinence, have been reported previously [2]. Nevertheless, the dictum "once a caesarean, always a caesarean" began changing approximately 30 years ago as improvements in obstetric care made a trial of labour after a previous caesarean delivery safer for both the mother and the infant [4]. It has been replaced by "once a caesarean, always a hospital delivery" [5]. Trial of delivery after one prior caesarean section is therefore considered a key method of reducing the overall caesarean section rate.

The existing data, however, about which route of delivery is most appropriate and safe for these womenVBAC or elective repeat caesarean delivery-are complex and conflicting [6]. Although neither route is risk-free, the crucial issue is to ensure better maternal and perinatal outcomes. In a trial of VBAC, the main adverse outcome is uterine rupture. Deciding when to attempt VBAC is a major decision and should be based on careful selection of patients after thorough counselling, estimation of patient's risk of uterine rupture and strict adherence to the most recent guidelines for managing labour in units where there are facilities for immediate access to surgery if complications arise. The purpose of this study in Yemen was to test the outcome of VBAC trial in women with one prior lower transverse caesarean and spontaneous onset of labour.

\section{Methods}

\section{Sample and setting}

This prospective controlled clinical study was carried out at Al-Thawra general hospital, Sana'a over a 1-year period (1 January to 31 December 2008). The criteria for selection of women to undergo trail of VBAC in this hospital are similar to the American Congress of Obstetricians and Gynecologists (ACOG) guidelines [4]. However, induction of labour using prostaglandins is totally avoided and oxytocin for augmentation of labour is occasionally given in small doses and under careful observation.

For this study, we selected women who had only one previous caesarean section and were considered candidates for trail of VBAC. We further selected the women to include only those who were at term (defined as 37 completed weeks up to 40 weeks), determined by the last menstrual period and/or first trimester ultrasonography, and who had spontaneous onset of labour (defined as cervical dilatation of $>4 \mathrm{~cm}$, with regular uterine contractions of $3+$ per $10 \mathrm{~min}$ lasting $40 \mathrm{~s}$ or more). Those who did not have spontaneous onset of labour, did not reach term or had other obstetric or medical indications for caesarean section were excluded from the study. There were no post-date pregnancies noted in this study.

During the study period there were 636 women who had undergone previous caesarean section. Out of them, 357 women (65.1\%) fulfilled our criteria and were included in the study. A matched control group of 158 women without previous uterine incision was selected.
They were matched for age, parity, gestational age, birth weight, Apgar score, use of oxytocin and mode of delivery. Three cases in the control group developed intrapartum fetal distress and were restored to the operating theatre for abdominal delivery, leaving 155 control women who completed the study.

Informed consent for participation in the study was taken from each participant and hospital ethical committee clearance was obtained.

\section{Data collection}

Every participant received a thorough history, clinical and obstetric examination. The data retrieved included: maternal age, parity, gestational age, indications for previous caesarean section, circumstances surrounding the previous delivery, type of uterine incision, interval since the previous caesarean and previous vaginal delivery before or after the caesarean section. We always assess pelvic adequacy using digital pelvimetry.

During the trial of labour, the senior physician responsible for the labour room was informed about the case. An intravenous line was established and maintained and intravenous infusion of $5 \%$ dextrose in water was given. At least 1 unit of blood was typed and crossmatched for each woman. For those women in both groups who presented early in the first stage (cervical dilatation $>4$ but $<7 \mathrm{~cm}$ ) the partogram was established and the fetal and maternal conditions were assessed and plotted regularly. For the other women, fetal cardiac activity, maternal vital signs and uterine contractions were assessed every $30 \mathrm{~min}$ in the first stage and $15 \mathrm{~min}$ in the second stage. The uterine scar was assessed every $30 \mathrm{~min}$ by noting maternal tachycardia, scar tenderness, fetal tachycardia, haematuria, vaginal bleeding and loss of the presenting part on vaginal examination. The progress of labour was assessed by abdominal and/ or vaginal examination 4 hourly in the first stage and more frequently in the 
second stage or when membranes were ruptured or bleeding ensued. This monitoring was continued throughout the trial of labour. Our policy to augment women with oxytocin during VBAC attempt is to infuse oxytocin 2.5 units in $500 \mathrm{~mL}$ of dextrose (or normal saline) at 10 drops/ $\min (2.5 \mathrm{mIU} / \mathrm{min})$ and increase the infusion rate by 10 drops/min every 30 min until a good uterine contractions pattern is established. All the women in our study responded to the first dose without further increment. All women had cardiotocography monitoring. Pain relief was given on the form of intramuscular injection of tramadol hydrochloride. Epidural analgesia was not available.

The outcome measures were the duration of first and second stage of labour, intrapartum complications, Apgarscore, birth weight, postpartum haemorrhage, uterine separation, need for blood transfusion and length of hospital stay.

\section{Statistical analysis}

Data were analysed using Stata, version 10. The data were presented as mean and standard deviation (SD) and percentages when appropriate. Differences in means were tested by Student $t$-test. Chi-squared tests were used to compare frequencies. Fisher exact test was used when appropriate. Statistical significance was taken as $P$ value $<0.05$.

\section{Results}

In the study group, 311 out of 357 women were delivered vaginally, giving a VBAC success rate of $87.1 \%$. The remaining 46 women (12.9\%) were delivered by repeat caesarean section, mainly due to intrapartum fetal distress. Of the women who successfully delivered vaginally, 224 (72.0\%) were admitted during the first stage of labour and 67 women $(22.0 \%)$ in the second stage versus $122(78.7 \%)$ and $33(21.3 \%)$ respectively in the control group. There were no significant differences between the study group and control group in terms of age, parity, gestational age or obstetric and medical history (Table 1) $(P>0.5)$.

Oxytocin was used to augment labour in 31 cases (10.0\%) (Table 1) but there was no uterine rupture recorded in these cases. Overall there were 3 cases (1.0\%) of uterine dehiscence and 1 case

\begin{tabular}{|c|c|c|c|c|c|}
\hline \multirow[t]{2}{*}{ Variable } & \multicolumn{2}{|c|}{$\begin{array}{l}\text { Case group } \\
\quad(n=311)\end{array}$} & \multicolumn{2}{|c|}{$\begin{array}{l}\text { Control group } \\
\quad(n=155)\end{array}$} & \multirow[t]{2}{*}{$P$-value ${ }^{a}$} \\
\hline & Mean & SD & Mean & SD & \\
\hline Age (years) & 23.3 & 5.3 & 23.1 & 8.7 & NS \\
\hline Parity & 2.9 & 1.0 & 2.8 & 1.2 & NS \\
\hline \multirow[t]{2}{*}{ Gestational age (weeks) } & 38.4 & 3.1 & 38.7 & 0.5 & NS \\
\hline & No. & $\%$ & No. & $\%$ & \\
\hline Oxytocin & & & & & $<0.001$ \\
\hline No & 280 & 90.0 & 74 & 47.7 & \\
\hline Yes & 31 & 10.0 & 81 & 52.3 & \\
\hline Birth weight (g) & & & & & NS \\
\hline$\leq 2500$ & 63 & 20.3 & 21 & 13.5 & \\
\hline$>2500-3500$ & 239 & 76.8 & 123 & 79.4 & \\
\hline$>3500$ & 9 & 2.9 & 11 & 7.1 & \\
\hline Apgar score & & & & & NS \\
\hline$<6$ & 18 & 5.8 & 7 & 4.5 & \\
\hline $6-8$ & 161 & 51.8 & 78 & 50.3 & \\
\hline$>8$ & 131 & 42.1 & 70 & 45.2 & \\
\hline Postpartum complications & & & & & NS \\
\hline Dehiscence & 3 & 1.0 & 0 & 0.0 & \\
\hline Uterine rupture & 1 & 0.3 & 0 & 0.0 & \\
\hline Blood transfusion & 2 & 0.6 & 0 & 0.0 & \\
\hline Length of hospital stay (hours) & & & & & $N S^{b}$ \\
\hline 2 & 287 & 92.3 & 148 & 95.5 & \\
\hline$>2-4$ & 17 & 5.5 & 0 & 0.0 & \\
\hline$>4$ & 7 & 2.3 & 7 & 4.5 & \\
\hline
\end{tabular}

${ }^{a} \chi^{2}$ test; ${ }^{b}$ Fisher exact test.

$S D=$ standard deviation; $N S=$ not significant . 
(0.3\%) of uterine rupture among the VBAC group. There were no maternal deaths and only 1 stillbirth after the case of uterine rupture. There was no significant difference between the groups in Apgar scores; $5.8 \%$ of neonates in the VBAC trial group had Apgar score < 6 compared with $4.5 \%$ in the control group $(P>0.05)$. We found 9 neonates (2.9\%) weighed $>3500 \mathrm{~g}$ but $<4000 \mathrm{~g}$ in the VBAC group.

The mean duration of the first and second stages of labour in the study group were 146.2 (SD 74.9) and 30.7 (SD 6.3) min respectively (Table 2 ). In the control group the mean duration of the first and second stages of labour were 146.7 (SD 68.7) and 29.8 (SD 7.4) min respectively. These differences were not statistically significant $(P>0.5)$.

There were 67 women $(21.5 \%)$ in the study group who had already experienced at least one vaginal delivery after their first caesarean section; 63 delivered vaginally, giving a VBAC success rate of $94.0 \%$. The mean duration of the first and second stages of labour in these women were 110.5 (SD 63.3) and 16.1 (SD 4.6) min respectively.

\section{Discussion}

Al-Thawra general hospital is the biggest public hospital in Yemen. It is a university-affiliated tertiary care level facility. The labour ward in the hospital accepts both booked and unbooked pregnant women and many complicated and mismanaged cases are referred to us.
The majority of women referred suffer various complications in their first delivery with caesarean section, such as obstructed labour, neglected transverse lie with hand prolapse, obstetric haemorrhage, prolonged rupture of membranes ( $>24$ hours), infection, fetal distress and prolonged labour. These women had been refereed directly from a local primary health unit in rural areas, often unbooked, or they had been mismanaged by untrained birth attendants and were given high doses of oxytocin at home. In these situations, they are often managed in hospital by primary caesarean section. In subsequent pregnancies, these women may seek early booking and special management both antenatally and in labour and delivery. These women are often very young and poorly educated. When they come again to the hospital with one previous lower segment transverse caesarean section, a trial of VBAC is offered, depending on the selection criteria, after proper counselling and assessment.

During the study period the rate of caesarean section in the hospital was $17.1 \%$ for all 12069 deliveries. The success rate of VBAC trial was $87.1 \%$. It is comparable to other similar studies. For example, Flamm et al. demonstrated that patients presenting with dilation $\geq 4 \mathrm{~cm}$ had an $86 \%$ success rate of VBAC $[1,7]$. Although a high success rates indicates a better maternal outcome [7], these rates often apply to a selected population [8] and the overall outcome measures should include certain other deliveryrelated perinatal complications, such as hypoxic ischaemic encephalopathy.
The mean duration of the first and second stages of labour were similar in both groups, which indicates that the previous caesarean section did not prolong labour in the next pregnancy. This result is consistent with other study findings [9].

Oxytocin was used to augment labour in $10.0 \%$ of women and there were no cases of uterine rupture recorded in these women. No significant association has been reported between exposure to oxytocin and the risk of uterine rupture [1]. However, the relationship between oxytocin and uterine rupture is dosedependent, and the ACOG has warned that excessive use of oxytocin raises the risk of uterine rupture [4].

For women who had already had a vaginal delivery after their first caesarean section the VBAC success rate was 94.0\% and the duration of the first and second stages of labour was shorter than for women who had their first VBAC. These findings are consistent with most studies reviewed [10] and may encourage patients and obstetricians to choose VBAC trial with more confidence when other risk factors are excluded.

Uterine rupture is the most likely complication related to VBAC trial. Most studies report the incidence of uterine rupture as between $0.5 \%-1 \%$ in women with one prior transverse lower segment caesarean section [11]. However, the incidence is higher when the previous incision is classical, when there has been more one previous caesarean section, with induction of labour or with shorter interpregnancy intervals [4]. In

\begin{tabular}{|c|c|c|c|c|c|}
\hline \multirow[t]{2}{*}{ Stage of labour } & \multicolumn{2}{|r|}{$\begin{array}{l}\text { Case group } \\
\quad(n=311)\end{array}$} & \multicolumn{2}{|c|}{$\begin{array}{l}\text { Control group } \\
(n=155)\end{array}$} & \multirow[t]{2}{*}{$P$-value ${ }^{a}$} \\
\hline & No. & $\begin{array}{l}\text { Mean (SD) duration } \\
(\text { min) }\end{array}$ & No. & $\begin{array}{l}\text { Mean (SD) duration } \\
(\mathrm{min})\end{array}$ & \\
\hline 1st stage & 224 & $146.2(74.9)$ & 122 & $146.7(68.7)$ & NS \\
\hline 2nd stage & 67 & $30.7(6.3)$ & 33 & $29.8(7.4)$ & \\
\hline
\end{tabular}

${ }^{a} \chi^{2}$ test.

$S D=$ standard deviation $; N S=$ not significant 
our study, 3 cases (1.0\%) were complicated by uterine dehiscence and 1 case $(0.3 \%)$ suffered uterine rupture. The latter case was discovered intrapartum when the woman developed sudden acute lower abdominal pain, tenderness and fetal distress. Immediate caesarean section was performed and complete rupture was found along with the dead baby. The mother was managed by hysterectomy. All 3 cases whose delivery was complicated by uterine dehiscence were discovered postpartum during exploration of the uterus and managed by rent repair. It is useful to note that in the rupture case that we found no clear obstetric, medical or social factors that could be linked to uterine rupture. However, other risk factors may have been present and additional studies are required to investigate cases of uterine rupture.

The perinatal outcomes in our study showed 1 stillbirth (0.3\%) in the VBAC group after the case of uterine rupture.
However, 5.8\% of neonates had Apger score $<6$ compared with $4.5 \%$ in the control group, a difference which was not statistically significant. Our findings reinforce similar previous studies suggesting that vaginal delivery after one caesarean section is safe as regards neonatal outcomes [12].

We found 9 neonates (2.9\%) weighed more than $3500 \mathrm{~g}$ but $<4000 \mathrm{~g}$. This finding shows that the estimation of fetalweight at term is relatively inaccurate whether done clinically or radiologically. Moreover, since the exact birth weight is only known after the delivery has occurred, this could limit the usefulness of birth weight as a predictor in clinical decision-making. Thus, birth weight may only be helpful when other predictors collectively are taken into consideration. Nevertheless, it implies that a women with one prior caesarean section and estimated fetal weight of $>3500 \mathrm{~g}$ but $<4000$ g can be strongly encouraged to undergo VBAC attempt [11].
There were no maternal deaths in either group. However, our results are based on data from a single setting for those women presenting to the hospital with previous one previous caesarean section and may not be generalizable to other locations.

\section{Conclusion}

On the basis of these results, we conclude that for selected cases with one prior lower segment caesarean section who present in spontaneous active labour, a trial of vaginal delivery may have a high success rate $(>85 \%)$ with no increased risk of maternal and fetal morbidity or mortality. The duration of labour for these women was similar to normal deliveries. Our findings may encourage obstetricians to tolerate VBAC and raise the threshold for recommending caesarean section if low-risk patients are carefully selected.

\section{References}

1. Flamm BL, Geiger AM. Vaginal birth after cesarean delivery: an admission scoring system. Obstetrics and Gynecology, 1997, 90:907-910

2. McMahon MJ et al. Comparison of a trial of labor with an elective second Cesarean section. New England Journal of Medicine, 1996, 335:689-695.

3. Avery MD, Carr CA, Burkhardt P. Vaginal birth after cesarean section: a pilot study of outcome in women receiving midwifery care. Journal of Midwifery and Women's Health, 2004, 49:113-117.

4. American College of Obstetricians and Gynecologists. ACOG practice bulletin no. 54. Vaginal birth after previous cesarean delivery. Obstetrics and Gynecology, 2004, 104:203-212.

5. Dodd J, Crowther CA. VBAC: a survey of practice in Australia and New Zealand. Australian and New Zealand Journal of Obstetrics and Gynaecology, 2003, 43:226-231.

6. Gordan CS. Delivery after cesarean section, In: Studd J, ed. Progress in obstetrics and gynaecology. Volume 17. Edinburgh, Churchill Livingstone, 2006:245-263.

7. Aaron BC. Vaginal birth after cesarean delivery. Medscape reference [online article] (http://emedicine.medscape.com/ article/272187-overview, accessed 28 May 2011).
8. Vaginal birth after previous cesarean delivery. Number 5, July 1999 (replaces practice bulletin number 2, October 1998). Clinical management guidelines for obstetrician-gynecologists. American College of Obstetricians and Gynecologists. International Journal of Gynaecology and Obstetrics, 1999, 66(2):197-204.

9. Tripathi JB, Doshi HU. Pattern of cervical dilatation in women with a previous cesarean section. Journal of Obstetrics and Gynecology of India, 2005, 55(2):125-127.

10. Handler I, Bujold E. Effect of prior vaginal delivery or prior VBAC on obstetric outcomes in women undergoing trial of labor. Obstetrics and Gynecology, 2004, 104:273-277.

11. George AM et al. Maternal complications with vaginal birth after cesarean section: A multicenter study. American Journal of Obstetrics and Gynecology, 2005, 193:1656-1662.

12. Colm $\mathrm{O}^{\prime} \mathrm{H}$. VBAC outcome associated with standardized intrapartum protocol after one previous cesarean. American Journal of Obstetrics and Gynecology, 2005, 193:546. 